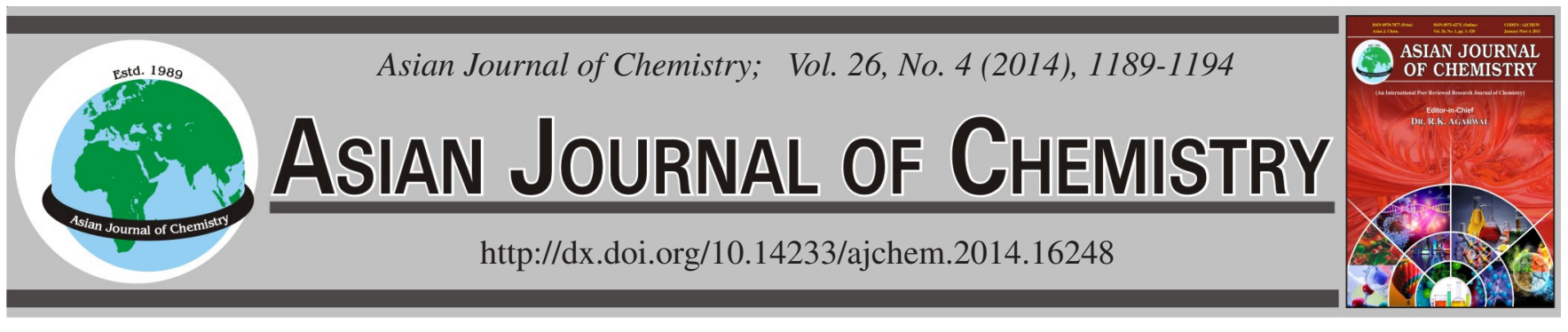

\title{
Separation and Enrichment of Flavonoids from Orange Peel Using Magnetic Nanoparticles
}

Xiuxiang Huang ${ }^{*}$, Junyu Lu, Chonglin Lu, Liangiang Wei and Qigian Li

College of Chemistry and Biology Engineering, He Chi University, Yizhou, Guangxi, P.R. China

*Corresponding author: Tel: +86 778 3141892; E-mail: hxx1372@sina.com

Received: 27 August 2013;

Accepted: 23 December 2013;

Published online: 15 February 2014;

AJC-14726

\begin{abstract}
In present study the $\mathrm{Fe}_{3} \mathrm{O}_{4}$ magnetic nanoparticles (MNPs) was acted as adsorption carrier to separate and concentrate flavonoids from the root extractive of orange peel. It involved synthesizing the $\mathrm{Fe}_{3} \mathrm{O}_{4}$ magnetic nanoparticle and extracting the flavonoids from orange peel. After magnetic separation and desorption process, the eluent was injected for HPLC analysis. Some parameters influenced extraction efficiency of flavonoids, including amount of $\mathrm{Fe}_{3} \mathrm{O}_{4}$ magnetic nanoparticles, shaking time and desorption condition were investigated. Under the optimal conditions, experimental result showed that the extraction efficiency of neohesperidin was higher than others flavonoids and the desorption ratio of neohesperidin is $89.3 \%$. This study demonstrated that the developed methods for separation and enrichment flavonoids was simple, lower cost and environmental friendly. Therefore, the proposed method had a potential for further application.
\end{abstract}

Keywords: $\mathrm{Fe}_{3} \mathrm{O}_{4}$ magnetic nanoparticles, Flavonoids, Extraction, Orange peel, HPLC.

\section{INTRODUCTION}

Orange (Citrus sinensis) peel is widely used as one of the traditional Chinese medicine. The composition contain in peel is complex, previous studies have described the presence of flavonoids as the major constituents of orange peel ${ }^{1,2}$. Modern medical and chemical studies have shown that flavonoids are important active components $\mathrm{s}^{3-5}$. According to modern pharmacology research, flavonoids have antitumor, antiinflammatory, antioxidant and free-radical scavenging properties ${ }^{6,7}$ and became a vital factor in protective against various diseases like cancer, hypertensive, cardiovascular disease and diabetes. Up to now, flavonoids have been successfully applied in health products, cosmetics and development of the natural medicine as well as in clinical application. Thus, an extensive prospect for further applications of flavone compounds is expected ${ }^{8}$.

Flavonoids have been considered to be a novel drugs and healthcare products due to its potential applications in pharmaceutical industry. There is an increasing demand for the production of flavonoids at high purities. Method for extraction and purification of natural flavone compounds have been reported, such as solvent extraction and column chromatographic procedures including silica gel, macroporous resin, etc ${ }^{9-11}$. All these methods are turned out to be a conventional and mature technique, but the disadvantages of these methods are tedious, time consuming, requiring multiple chromatographic steps on silica gel, macroporous resin column and high costs of operation $^{12}$. Current research is mainly focused on the development of new techniques and the application of novel materials with enhanced extraction efficiencies.

Recently, a series of absorption material with hydrogenbonding groups were synthesized based on the investigation of the hydrogen bonds interactions between adsorbent and adsorbate ${ }^{13}$. Nevertheless, certain adsorbates, such as flavonoids, have special structures which have multi-phenolic groups, as shown in Fig. 1. All the structures indicate that if there are some special functional groups such as hydroxyls on the surface of certain adsorbent to favour the hydrogen bond interaction between adsorbents and flavonoids, better separate and concentrate flavonoids would be achieved from the complicated system of crude extraction solution.

Great effort have been made in developing new materials for flavonoids extraction and eyes have been turned to the $\mathrm{Fe}_{3} \mathrm{O}_{4}$ magnetic nanoparticles (MNPs), which have been used to extract and purify flavonoids from various herbal sources due to it possesses the superiority of large surface area, excellent dispersibility in aqueous solution, easy retrieved from bulk solution by applying an external magnetic field with magnet and sustainable reuse ${ }^{14}$. Qing et al. $^{15}$ utilized baicalinfunctionalized magnetic nanoparticles for selectively extracting flavonoids from Rosa chinensis. Zhang and $\mathrm{Shi}^{16}$ developed a new solid-phase extraction method for magnetic retrieval of chitosan combined with high-performance liquid chromatography for the pre-concentration and determination of flavonoids in green tea beverage samples. Hiratsuka et al. ${ }^{17}$ prepared magnetic molecularly imprinted polymers for bisphenol A 


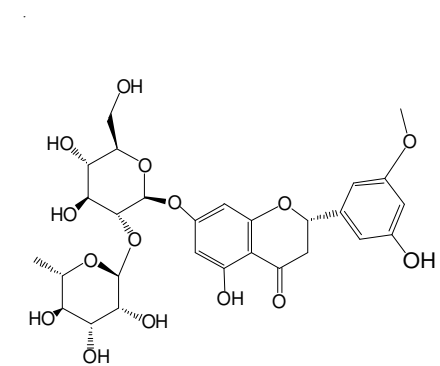

(A)

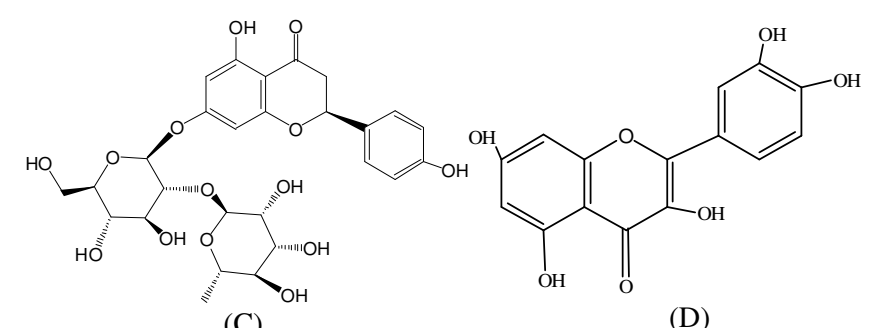

(C)

(D)

Fig. 1. Structure of flavonoids studied in this work: (A) rutin, (B) neohesperidin, (C) naringin, and (D) quercetin

and its analogues and their application to the assay of bisphenol $\mathrm{A}$ in river water. But the disadvantages of synthesis and applications of functionalized magnetic materials is time consuming as well, as they also require multiple steps of $\mathrm{Fe}_{3} \mathrm{O}_{4} \mathrm{MNPs}$ surface modification and expensive chromatographic matrices thus resulting in high costs of operation. In another way, the surface of $\mathrm{Fe}_{3} \mathrm{O}_{4}$ MNPs can exist a number of hydroxyl group that may also in favoring of $\mathrm{H}$-bonding as well as other uncovalent bond, it means that the bare $\mathrm{Fe}_{3} \mathrm{O}_{4}$ MNPs may be used as a absorbent directly. To the best of our knowledge, there has been no report on using the $\mathrm{Fe}_{3} \mathrm{O}_{4}$ MNPs separate and concentrate flavonoids from orange peel.

Herein, we present our study of developing a simple and effective method for separate and concentrate flavonoids from orange peel by using bare $\mathrm{Fe}_{3} \mathrm{O}_{4} \mathrm{MNPs}$ directly. In our works, the influence of relevant parameters were investigated and optimized in detail, including dosage of $\mathrm{Fe}_{3} \mathrm{O}_{4} \mathrm{MNPs}$, shaking time and desorption condition. As revealed by the results, the present method may be a promising approach to separation and enrichment the flavonoids.

\section{EXPERIMENTAL}

Orange peel was collected from local market (Yizhou, China). Rutine, neohesperidin, naringin, quercetin, HPLCgrade methanol and acetonitrile were obtained from Shanghai Chemical Reagents Corporation (Shanghai, China). Iron(II) chloride tetrahydrate $\left(\mathrm{FeCl}_{2} \cdot 4 \mathrm{H}_{2} \mathrm{O}\right)$, iron(III) chloride hexahydrate $\left(\mathrm{FeCl}_{3} \cdot 6 \mathrm{H}_{2} \mathrm{O}\right)$, glacial acetic acid, ammonium hydroxide, absolute alcohol, hydrochloric acid, sodium hydroxide, etc. were in analytical grade. Ultrapure water used for the preparation of solutions was produced by a Yue Chun water system (chengdu, China). All samples were filtered (MFS-25, 0.22 $\mu \mathrm{m}$, Shanghai, China) before being injected into the HPLC system.

The $\mathrm{Fe}_{3} \mathrm{O}_{4}$ MNPs were characterized by Nicolet 6700 Fourier transform infrared spectrometer (FT-IR, USA), The $\mathrm{X}$-ray powder diffraction (XRD) spectra were collected on an X'Pert Pro diffractometer (Philips, Holand). HPLC was performed with an Agilent Technologies (Santa Clara, USA) 1200 liquid chromatograph equipped with a quaternary solvent-delivery system, an autosampler and a UV detector. Hystar 3.1 software for chromatography and hyphenated techniques, was used for data acquisition. An Agilent Zorbax SB-C18 column $(100 \times 4.6 \mathrm{~mm}), 5 \mu \mathrm{m}$ particles was used for all analysis. A KQ2200DE ultrasonic bath with temperature control (Kunshan Shumei Ultrasonic Instrument, Suzhou, China) was used to disperse the nanoparticles in solution. An $\mathrm{Nd}-\mathrm{Fe}-\mathrm{B}$ magnet $(8.0 \times 6.0 \times 1.6 \mathrm{~mm})$ was used for magnetic separation. $\mathrm{pH}-$ meter (pHS-3B, Shanghai, China) and a magnet $(60 \times 10 \times 4 \mathrm{~mm})$ were used.

Chromatographic conditions for flavonoid analysis: The detection wavelength was set at $300 \mathrm{~nm}$ and the analysis temperature was $30^{\circ} \mathrm{C}$. The mobile phase was a gradient prepared from methanol (component A) and $0.1 \%(\mathrm{v} / \mathrm{v})$ aqueous acetic acid (component B). The composition of the gradient was A-B 15:85 at $0 \mathrm{~min}, 30: 70$ at $4 \mathrm{~min}, 45: 55$ at $8 \mathrm{~min}, 65: 35$ at $12 \mathrm{~min}$ and keep for $6 \mathrm{~min}, 15: 85$ at $8 \mathrm{~min}$, duration of reequilibration between runs was $10 \mathrm{~min}$. The flow rate was set at $0.6 \mathrm{~mL} \mathrm{~min} \mathrm{~m}^{-1}$ and $5 \mu \mathrm{L}$ volumes were injected. Standard calibration curves of each flavonoid were given in Table-1, where $\mathrm{X}$ is the content of the flavonoids and $\mathrm{Y}$ is the peak area.

Preparation of $\mathrm{Fe}_{3} \mathrm{O}_{4}$ magnetite nanoparticles: The $\mathrm{Fe}_{3} \mathrm{O}_{4}$ MNPs were prepared by chemical co-precipitation method ${ }^{18}$. Briefly, $\mathrm{FeCl}_{3} \cdot 6 \mathrm{H}_{2} \mathrm{O}(5.4 \mathrm{~g}), \mathrm{FeCl}_{2} \cdot 4 \mathrm{H}_{2} \mathrm{O}(2 \mathrm{~g})$ and $12 \mathrm{M}$ hydrochloric acid $(0.85 \mathrm{~mL})$ were dissolved in the flask with $150 \mathrm{~mL}$ deionized water. Then, $12 \mathrm{~mL}$ of $26.5 \%$ aqueous ammonia was added rapidly into the solution under nitrogen atmosphere with vigorous stirring. The colour of bulk solution turn black immediately, followed by a dropwise addition of ammonia until the solution $\mathrm{pH}$ reached 10 . The solution was promptly heated to $85^{\circ} \mathrm{C}$ and maintained at that temperature for $1 \mathrm{~h}$ and finally cooled slowly to room temperature. The obtained $\mathrm{Fe}_{3} \mathrm{O}_{4} \mathrm{MNPs}$ was separated from the reaction medium by a magnetic field, rinsed with deionized water and ethanol three times respectively. And finally dried in vacuum at $30^{\circ} \mathrm{C}$ for $8 \mathrm{~h}$.

Preparation of the crude extract of orange peel: The dried peel ( $5 \mathrm{~g}$ ) was grinded into small pieces $1-2 \mathrm{~mm}$ by using

TABLE-1

LINEAR RELATIONSHIPS BETWEEN PEAK AREA AND CONTENT OF THE FLAVONOIDS

\begin{tabular}{lccc}
\hline Analytes & Calibration equations & Correlation coefficient $(\mathrm{R})$ & Linearity range $\left(\mathrm{mmol} \mathrm{L}^{-1}\right)$ \\
\hline Naringin & $\mathrm{Y}=202.65 X-5.034$ & 0.9937 & $0.001-0.1$ \\
Rutin & $\mathrm{Y}=417.69 \mathrm{X}-5.131$ & 0.9997 & $0.001-0.1$ \\
Neohesperidin & $\mathrm{Y}=456.58 \mathrm{X}-0.542$ & 0.9984 & $0.001-0.1$ \\
Quercetin & $\mathrm{Y}=272.42 \mathrm{X}-1.919$ & 0.9991 & $0.001-0.1$ \\
\hline \multicolumn{2}{l}{ Annotation: $\mathrm{X}$ is the content of the flavonoids and $\mathrm{Y}$ is the peak area; $\mathrm{R}$ is the correlation coefficient of the regression equation }
\end{tabular}


a crushing machine and placed in a sealed vessel by adding $30 \mathrm{~mL}$ of the ethanol-water (70:30, v/v) solvent, then the sealed vessel was placed in the ultrasonic cleaning bath for ultrasonic extraction for $0.5 \mathrm{~h} \mathrm{~min}$ at room temperature $\left(25^{\circ} \mathrm{C}\right)$. The suspension was filtered and the remaining powder was extracted two more times using $25 \mathrm{~mL}$ of the ethanol-water $(70: 30, \mathrm{v} / \mathrm{v})$ solvent. After filtration, the filtrate was diluted to $100 \mathrm{~mL}$ in a volumetric flask $(100 \mathrm{~mL})$ by the ethanol-water (70:30, v/v) solvent and stored at $4{ }^{\circ} \mathrm{C}$ before use.

Preparation of standard solution: Stock solutions of rutin, neohesperidin, naringin and quercetin $\left(0.24 \mathrm{mg} \mathrm{mL}^{-1}\right)$ were prepared as follows: $6 \mathrm{mg}$ of rutin, neohesperidin, naringin and quercetin was dissolved separately in ethanolwater $(70: 30, \mathrm{v} / \mathrm{v})$ solution. Then the solution was diluted to $25 \mathrm{~mL}$ in a volumetric flask $(25 \mathrm{~mL})$ by ethanol-water (70:30, v/v) solvent and stored at $4{ }^{\circ} \mathrm{C}$ before use.

$\mathrm{Fe}_{3} \mathrm{O}_{4}$ MNPs extraction procedure: The extraction procedure was schematically described in Fig. $2.50 \mathrm{mg} \mathrm{Fe}_{3} \mathrm{O}_{4}$ MNPs was introduced into a sealed vessel and cleaned two times with $2 \mathrm{~mL}$ methanol and $2 \mathrm{~mL}$ ultrapure water in sequence, then $2 \mathrm{~mL}$ diluted crude extraction was added to the vessel and sonicated for $3 \mathrm{~min}$ to dispersed the $\mathrm{Fe}_{3} \mathrm{O}_{4} \mathrm{MNPs}$, the vessel was then shaken at $25{ }^{\circ} \mathrm{C}$ until adsorption equilibrium was reached. After that, a magnet was placed at the bottom of the vessel to collect the $\mathrm{Fe}_{3} \mathrm{O}_{4}$ MNPs from the solution. The concentration of the flavonoids in the supernatant solution was analyzed by HPLC.

The adsorbate saturated $\mathrm{Fe}_{3} \mathrm{O}_{4}$ MNPs was desorbed with $1 \mathrm{~mL}$ pH 3 methanol solution. Finally, the vessel was shaken for $8 \mathrm{~min}$ at $25^{\circ} \mathrm{C}$. After magnetic separating, the desorbed solutions were then analyzed by HPLC.

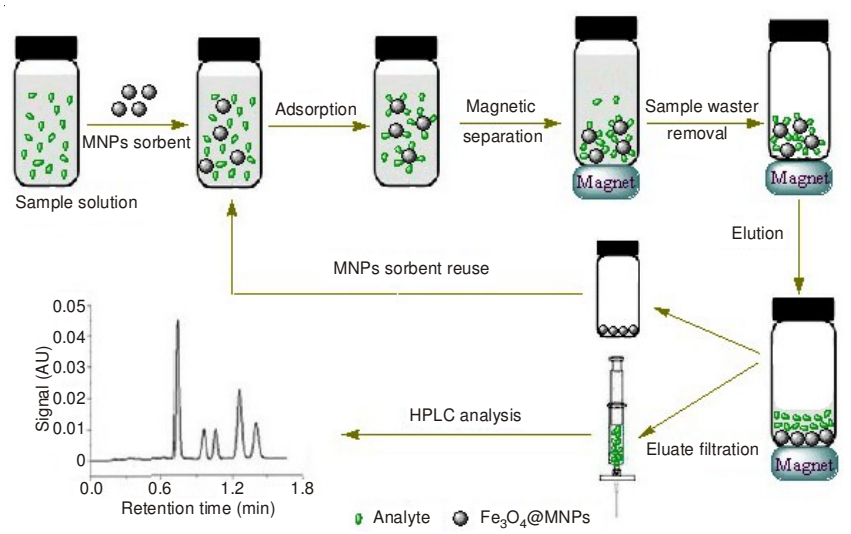

Fig. 2. Schematic diagram illustrates the magnetic extraction and HPLC analysis of flavonoids

\section{RESULTS AND DISCUSSION}

Characterization of the $\mathrm{Fe}_{3} \mathrm{O}_{4}$ MNPs: The synthesis of $\mathrm{Fe}_{3} \mathrm{O}_{4}$ MNPs was assessed both by means of FT-IR analysis and XRD spectra. FT-IR spectra of is shown in Fig. 3. As can be seen, the peak at about 3122,1624 and $586 \mathrm{~cm}^{-1}$ corresponding to the $\mathrm{O}-\mathrm{H}$ and $\mathrm{Fe}-\mathrm{O}$ stretching vibrations, respectively. The X-ray diffraction (XRD) patterns for the synthesized $\mathrm{Fe}_{3} \mathrm{O}_{4}$ MNPs are displayed in Fig. 3. The reflection peaks at $2 \theta=$ $30.26^{\circ}, 35.56^{\circ}, 43.32^{\circ}, 53.34^{\circ}, 57.26^{\circ}$ and $62.78^{\circ}$, respectively and can be ascribed to (220), (311), (400), (422), (511) and
(440) planes, which agreed well with the database of magnetite in the JCPDS-International Center for Diffraction Data (JCPDS Card: 19-629) file. It indicated that the $\mathrm{Fe}_{3} \mathrm{O}_{4}$ MNPs are crystalline materials.
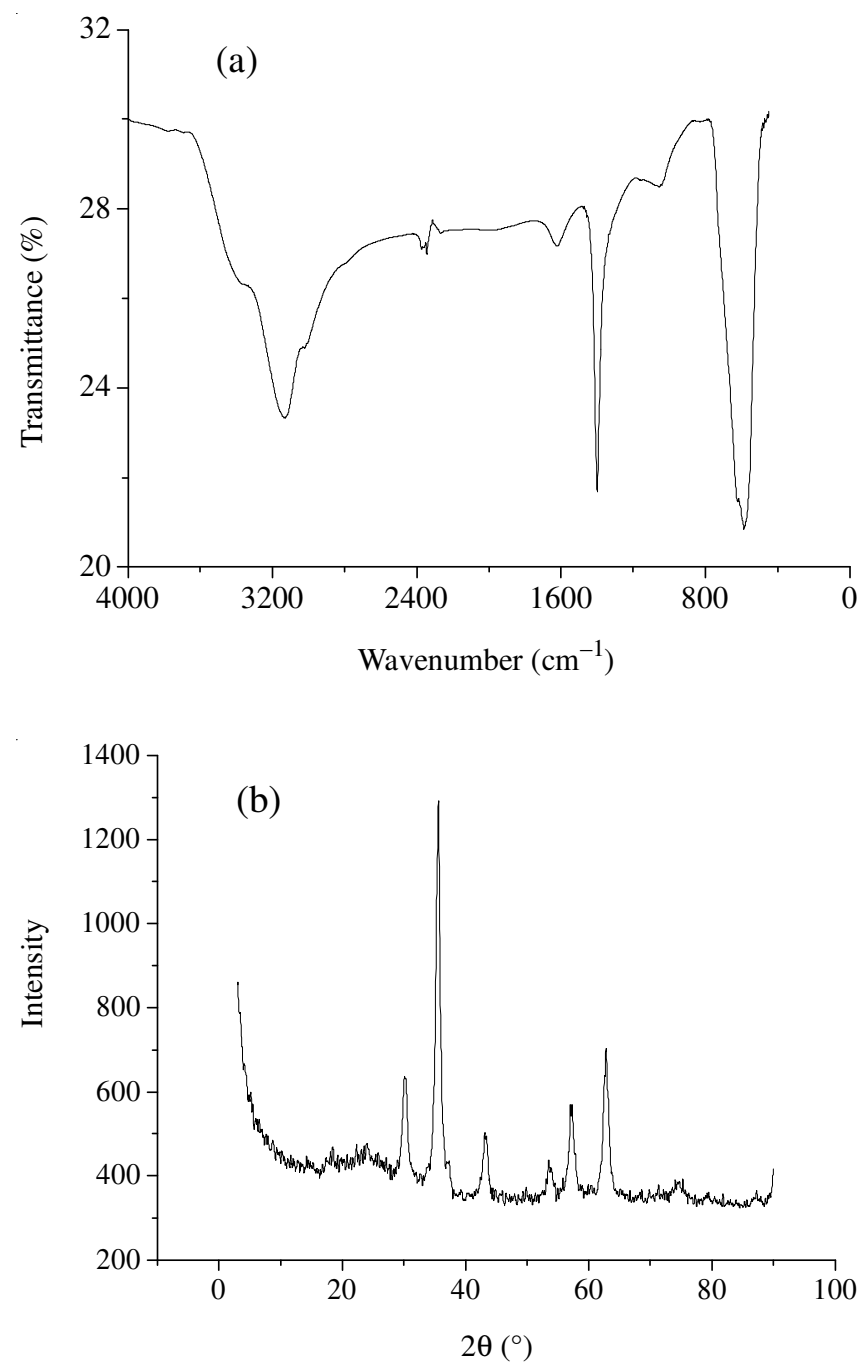

Fig. 3 FT-IR spectra (a) and XRD patterns (b) of $\mathrm{Fe}_{3} \mathrm{O}_{4} \mathrm{MNPs}$

Evaluation of magnetic ability of the $\mathrm{Fe}_{3} \mathrm{O}_{4}$ MNPs: For practical application of the $\mathrm{Fe}_{3} \mathrm{O}_{4}$ MNPs, it is important that the $\mathrm{Fe}_{3} \mathrm{O}_{4}$ MNPs should possess sufficient magnetic attraction. Therefore, we have tested as follow: $10 \mathrm{mg} \mathrm{Fe}_{3} \mathrm{O}_{4} \mathrm{MNPs}$ and $2 \mathrm{~mL}$ deionized water were added to a vial and placed the magnet beside the vial. It is found that the $\mathrm{Fe}_{3} \mathrm{O}_{4} \mathrm{MNPs}$ were quickly attracted to the wall of the vial in a few seconds, leaving the solution transparent. The results indicate that the $\mathrm{Fe}_{3} \mathrm{O}_{4}$ MNPs as sorbents can be thoroughly separated by an external magnetic field.

Optimization of $\mathrm{Fe}_{3} \mathrm{O}_{4}$ MNPs extraction conditions: In this study, the optimization was carried out by using naringin, rutin, neohesperidin and quercetin as model analytes. The parameters affecting the performance of the extraction, such as the amount of $\mathrm{Fe}_{3} \mathrm{O}_{4}$ MNPs, shaking time and desorption condition, were investigated and optimized.

In order to find out the appropriate amounts of $\mathrm{Fe}_{3} \mathrm{O}_{4}$ MNPs on adsorption of target analytes, different dosage of $\mathrm{Fe}_{3} \mathrm{O}_{4} \mathrm{MNPs}$ ranging from 10 to $70 \mathrm{mg}$ were used. As can be 
seem in Fig. 4, the effect of the amount of $\mathrm{Fe}_{3} \mathrm{O}_{4} \mathrm{MNPs}$ on the concentration of model analytes is significant and the concentration achieved by $50 \mathrm{mg} \mathrm{Fe}_{3} \mathrm{O}_{4} \mathrm{MNPs}$ are the highest. This can be attributed to a comprehension influence of the total surface area of the $\mathrm{Fe}_{3} \mathrm{O}_{4}$ MNPs and their dispersibility in sample solution. Based on this result, $50 \mathrm{mg}$ was selected as the final amount of $\mathrm{Fe}_{3} \mathrm{O}_{4}$ MNPs in the following experiments.

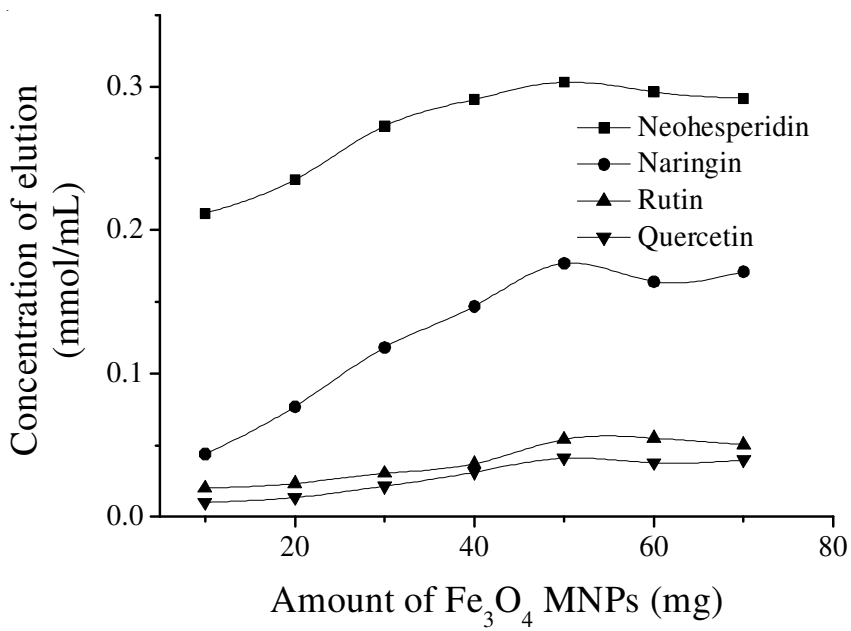

Fig. 4. Effect of the amount of $\mathrm{Fe}_{3} \mathrm{O}_{4} \mathrm{MNPs}$ on the concentration of elution, The adsorption time was 6 min

In the extraction process, the effect of shaking time was investigated. As shown in Fig. 5, it can be seen that the extraction concentration of model analytes all achieved their maximums at $6 \mathrm{~min}$. Therefore, a short shaking time of $6 \mathrm{~min}$ was selected for adsorption, which enables the target analytes to be saturated absorption on the $\mathrm{Fe}_{3} \mathrm{O}_{4}$ MNPs.

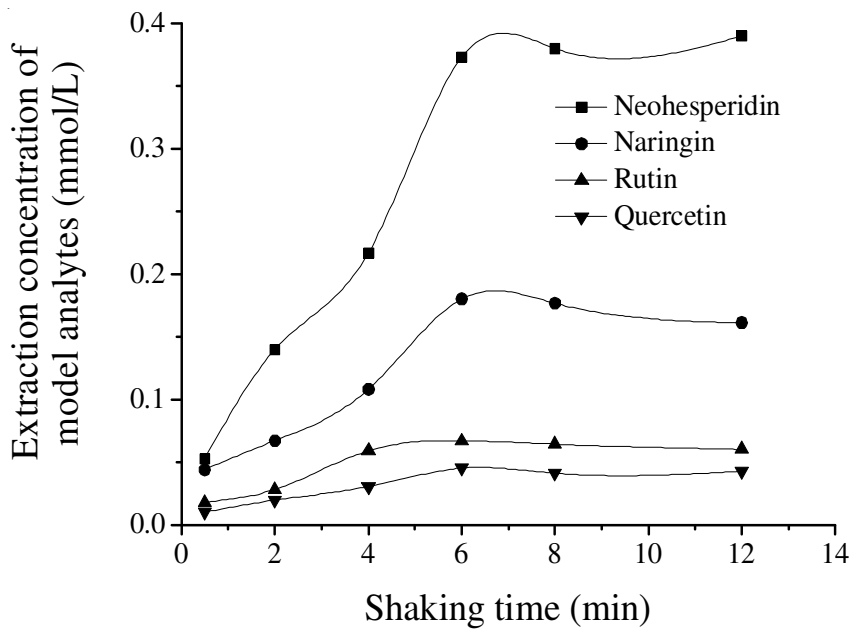

Fig. 5. Effect of the shaking time on the extraction concentration of model analytes

In addition, the effect of desorption time in the range of 2-20 min was investigated to improve extraction efficiency. The results shown in Fig. 6 indicated that, the concentration of model analytes increase with the increasing desorption time, up to $8 \mathrm{~min}$. After $8 \mathrm{~min}$, most of the analytes concentration have no significant change. Thus, the desorption time of $8 \mathrm{~min}$ was considered in the following studies.

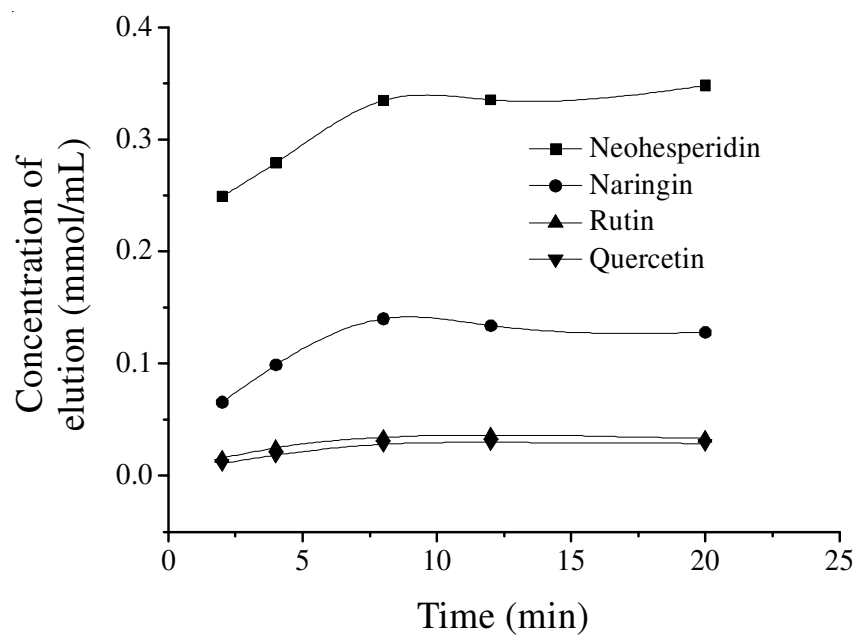

Fig. 6. Effect of different desorption times on the concentration of elution

The $\mathrm{pH}$ of elute solution plays an important role for desorption of target analytes by affecting the charged species and density on the $\mathrm{Fe}_{3} \mathrm{O}_{4}$ MNPs surface. In this sense, $\mathrm{pH}$ values ranging from 3 to 11 were studied. As can be seen in Fig. 7, the concentration of model analytes decreased with increasing $\mathrm{pH}$. This result can be attributed to the target analytes ionization and decreases repulsion on the surface of $\mathrm{Fe}_{3} \mathrm{O}_{4} \mathrm{MNPs}$. At $\mathrm{pH}$ values below 2 the solution turns dark brown indicating partial decomposition of $\mathrm{Fe}_{3} \mathrm{O}_{4}$ MNPs by the excess of acetic acid while at $\mathrm{pH}$ above 12 the $\mathrm{Fe}_{3} \mathrm{O}_{4}$ MNPs were found to lose their magnetic properties ${ }^{19}$. According to these results, a $\mathrm{pH}$ of 3 was selected for subsequent experiments.

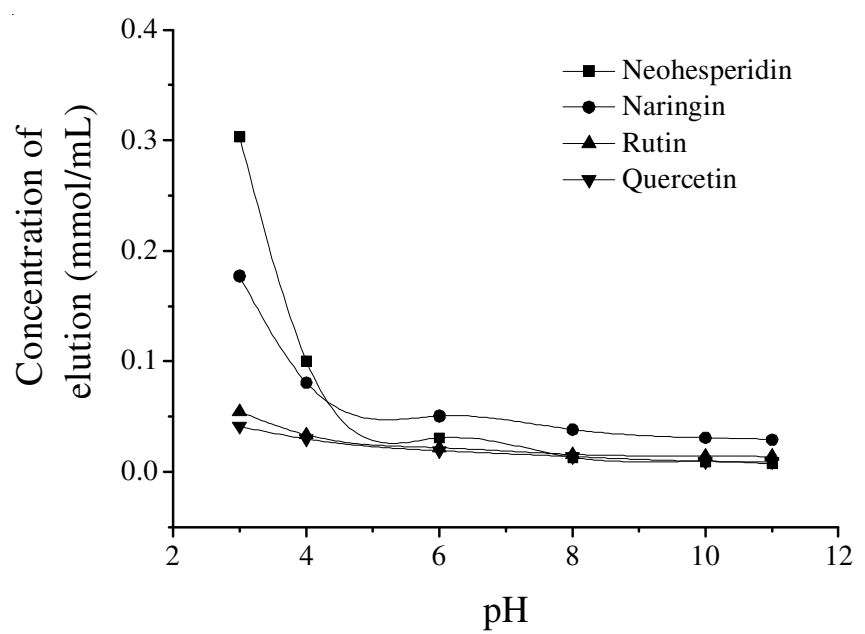

Fig. 7. Effect of $\mathrm{pH}$ on the concentration of elution. $\mathrm{Fe}_{3} \mathrm{O}_{4} \mathrm{MNPs}$ amount, $0.1 \mathrm{~g}$

To ensure the complete desorption of the target analyte from the $\mathrm{Fe}_{3} \mathrm{O}_{4}$ MNPs, a suitable eluent should be used. For this purpose, three different eluents were investigated: methanol, ethanol and acetonitrile. Fig. 8 showed that it is evident that methanol gave the much higher concentration of model analytes than other eluents. This result possibly due to methanol was more efficient in eliminating hydrogen bonded between target analytes and the $\mathrm{Fe}_{3} \mathrm{O}_{4}$ MNPs. Thus, methanol was chosen as the desorption solvent.

To remove the sample carry-over problem, after desorption, the used $\mathrm{Fe}_{3} \mathrm{O}_{4}$ MNPs were washed twice with $2 \mathrm{~mL}$ methanol and then with $2 \mathrm{~mL}$ water by shaking for $2 \mathrm{~min}$. 


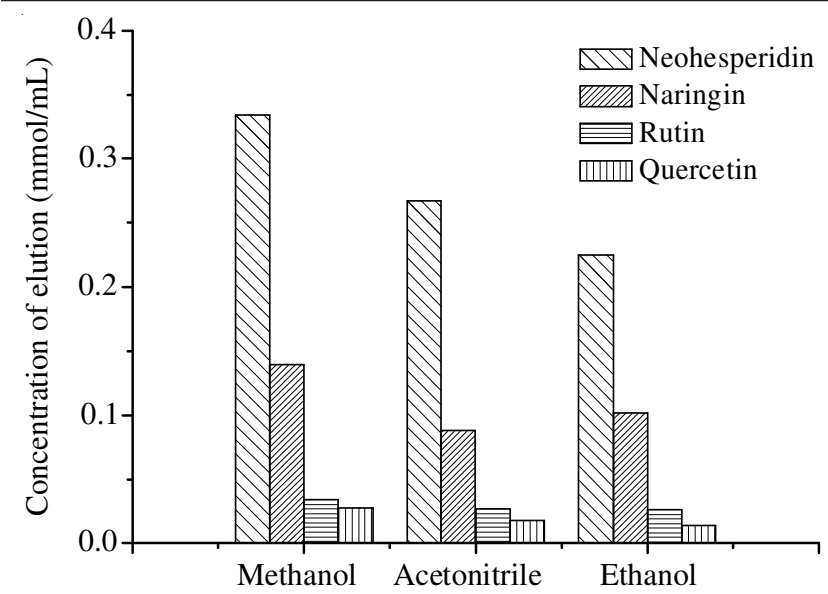

Fig. 8. Effect of different desorption solvents on the concentration of elution

After washing, no sample carry-over was detected and the $\mathrm{Fe}_{3} \mathrm{O}_{4}$ MNPs can be reused without a significant decrease of the extraction efficiency.

HPLC analysis of flavonoids from orange peel: In order to assess the $\mathrm{Fe}_{3} \mathrm{O}_{4}$ MNPs extraction flavonoids performance, we selected the standards including naringin, rutin, neohesperidin and quercetin as model analytes in our experiment. The HPLC profile of reference samples before and after using $\mathrm{Fe}_{3} \mathrm{O}_{4}$ MNPs enrichment were displayed in Fig. 9. By comparing the two chromatograms shown in Fig. 9a and b, it can be seen that the concentration of neohesperidin was obviously improved as compared to that without using the $\mathrm{Fe}_{3} \mathrm{O}_{4}$ MNPs extract, when the content of naringin, rutin and quercetin have no significant changes. This phenomenon can be explained by the structurally different phenolic hydroxyl.

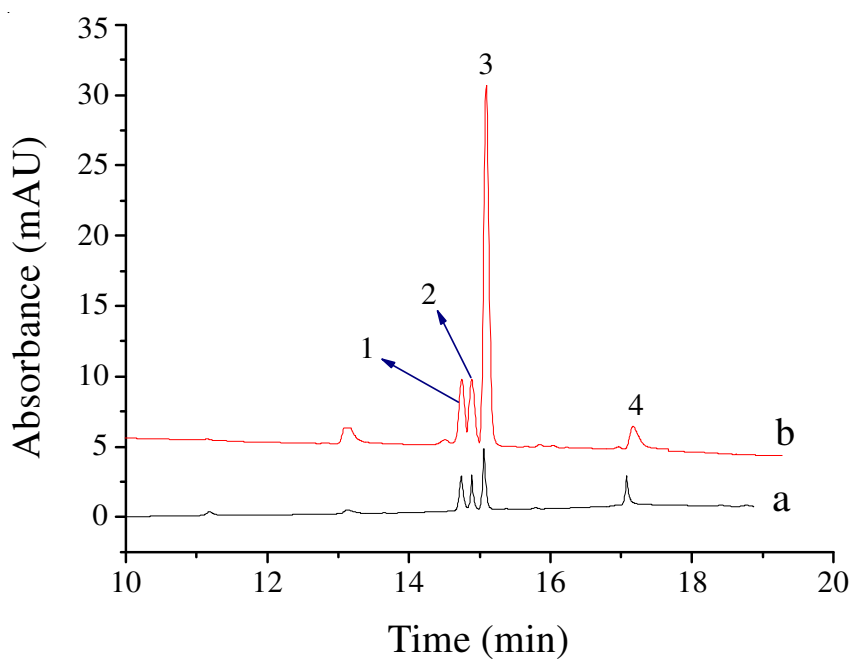

Fig. 9. Chromatograms of reference samples before (a) and after (b) using $\mathrm{Fe}_{3} \mathrm{O}_{4}$ MNPs extraction

To verify the possible application of the procedure presented above, this method was further applied to separate and concentrate flavonoids from orange peel. Nevertheless, to obtain a good separation of flavonoids from orange peel, the gradient elution is necessary due to their inherent structural diversity and different polarities. Most flavonoids presenting several ionisable hydroxyl groups with $\mathrm{pK}_{\alpha}$ values relatively close to each other but certainly greater than 4 , in order to minimize flavonoids ionization, using an acidic mobile phase was obligated ${ }^{20}$. According to this, the mobile phase was a gradient prepared from methanol and $0.1 \%(\mathrm{v} / \mathrm{v})$ aqueous acetic acid. Uder the optimized conditions, the result of HPLC analysis were shown in Fig. 10. As can be seen from Fig. 10A, the elution order is naringin, rutin, neohesperidin and quercetin. In addition, it can be seen that each peak was resolved from the neighboring peaks and displayed excellent peak symmetry and separation efficiency. Fig. 10B and C represent the HPLC separation of the crude extracts and the sample spiked with stander references. As can be seen from Fig. 10B and C, all components were obtained good separation and the content of rutin are the highest in the crude extracts. The retention time of naringin, rutin, neohesperidin and quercetin were $14.769,14.994,15.242$ and $17.334 \mathrm{~min}$, respectively. Thus, few interference from other components of the crude extracts were observed. As could be observed from Fig. 10D, the concentration of neohesperidin was improved and most compounds were remarkably removed after using the $\mathrm{Fe}_{3} \mathrm{O}_{4}$ MNPs separation and concentration procedure comparing with Fig. 10B. These result is likely due to their chemical structures with different phenolic hydroxyl and result in the different hydrogen-bonding interaction on the surface of the $\mathrm{Fe}_{3} \mathrm{O}_{4}$ MNPs.
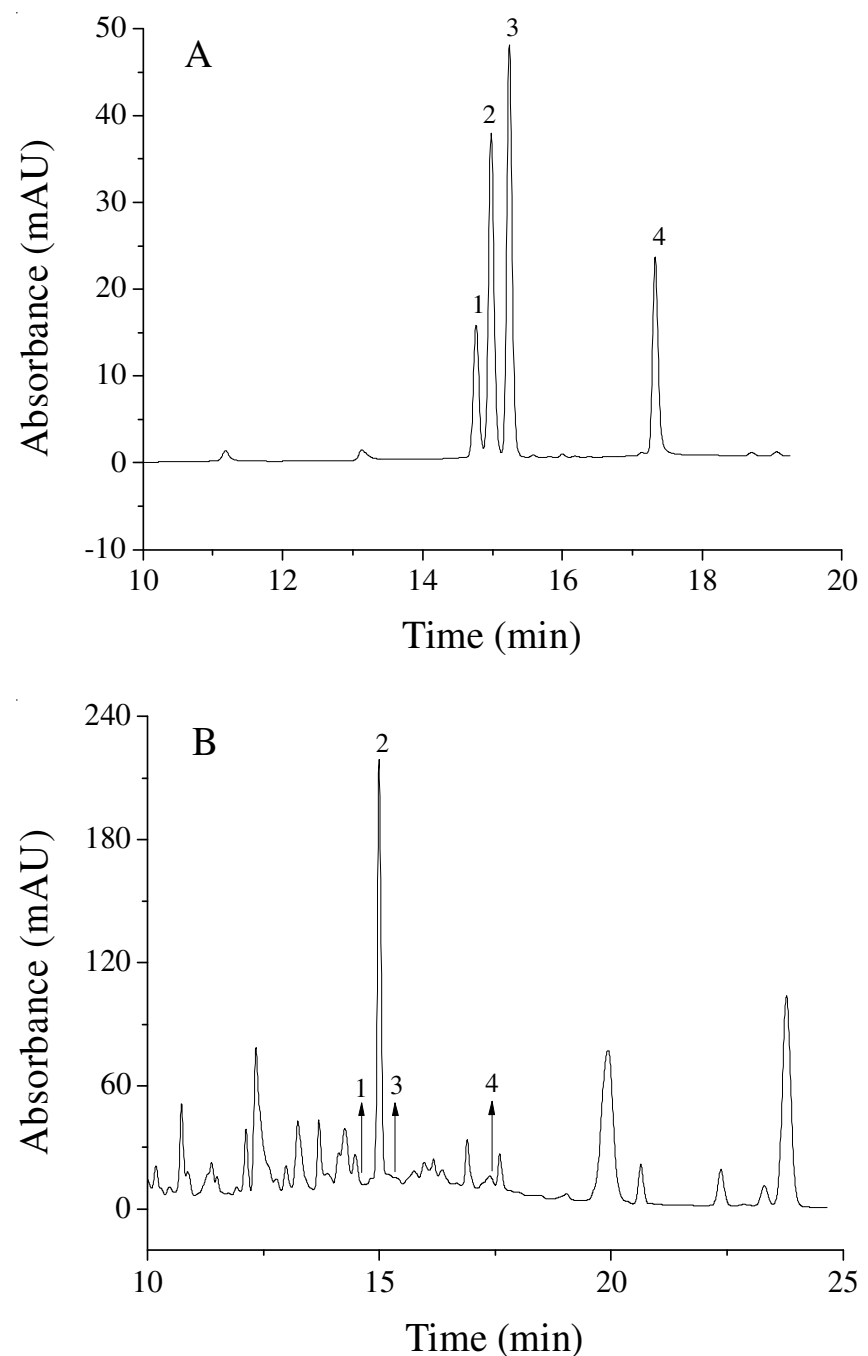

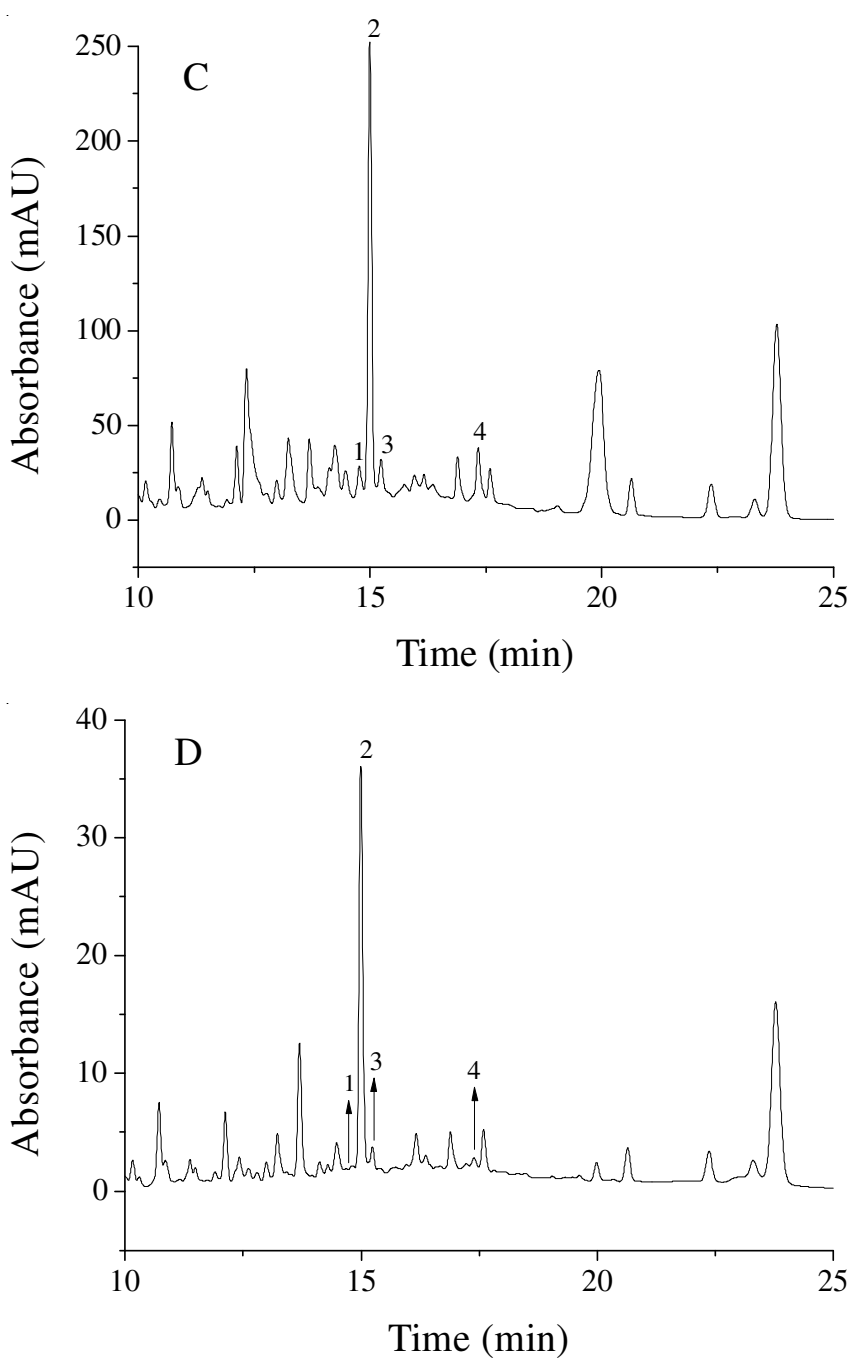

Fig. 10. Chromatograms were as follows: (A) standard references; (B) the crude extract; (C) the crude extract spiked with standard references; (D) after separation and concentration. 1, naringin; 2, rutin; 3, neohesperidin; 4, quercetin

\section{Conclusion}

In this work, a method based on $\mathrm{Fe}_{3} \mathrm{O}_{4}$ MNPs sorbents was developed for separation and enrichment flavonoids from orange peel. The effect of several factors were investigated to obtain optimization of the extraction and desorption conditions. The results of the experiments demonstrate that under the optimized conditions, $50 \mathrm{mg}$ of $\mathrm{Fe}_{3} \mathrm{O}_{4} \mathrm{MNPs}$, shaking time
6 min, desorption time $8 \mathrm{~min}, \mathrm{pH} 3$ and desorption solvent methanol, $\mathrm{Fe}_{3} \mathrm{O}_{4}$ MNPs offer higher extraction of the neohesperidin and the desorption ratio was $89.3 \%$. Thus, due to its easiness and simplicity, economic and environmental friendly, the present method may be a promising approach to separate and concentrate the flavonoids. In another aspect, the effect of $\mathrm{Fe}_{3} \mathrm{O}_{4}$ MNPs surface chemistry and morphology on the separation and enrichment of flavonoids from orange peel is worth of great effort to be made, which is now ongoing.

\section{ACKNOWLEDGEMENTS}

The financial support from the Guangxi Teaching Reform Project Program of Higher Education of China (No. 2013JGA218) and Youth Research Projects of He chi University of Guangxi, China (No. 2013B-N003) are gratefully acknowledged.

\section{REFERENCES}

1. M.K. Khan, M. Abert-Vian, A.-S. Fabiano-Tixier, O. Dangles and F. Chemat, Food Chem., 119, 851 (2010).

2. E.G. Haggag, I.I. Mahmoud, E.A. Abou-Moustafa and T.J. Mabry, Asian J. Chem., 11, 707 (1999).

3. X.T. Geng, P. Ren, G.P. Pi, R.F. Shi, Z. Yuan and C.H. Wang, J. Chromatogr. A, 1216, 8331 (2009).

4. C. Rice-Evans, Free Radic. Biol. Med., 36, 827 (2004).

5. B. Mello and M.D. Hubinger, Int. J. Food Sci. Technol., 47, 2510 (2012).

6. A.D. Ozsahin and O. Yilmaz, Asian J. Chem., 22, 6403 (2010).

7. W. Routray and V. Orsat, Food Bioprocess Technol., 5, 409 (2012).

8. E. de Rijke, P. Out, W.M.A. Niessen, F. Ariese, C. Gooijer and U.A.Th. Brinkman, J. Chromatogr. A, 1112, 31 (2006).

9. L.H. Wang, Y.H. Mei, F. Wang, X.S. Liu and Y. Chen, Separ. Purif. Tech., 77, 397 (2011).

10. M. Furusawa, H. Tsuchiya, M. Nagayama, T. Tanaka, K. Nakaya and M. Iinuma, J. Health Sci., 49, 475 (2003).

11. H. Bae, G.K. Jayaprakasha, J. Jifon and B.S. Patil, Food Chem., 130, 751 (2012).

12. X.T. Geng, P. Ren, G.P. Pi, R.F. Shi, Z. Yuan and C.H. Wang, J. Chromatogr. A, 1216, 8331 (2009).

13. Y. Zhang, S. Li, X. Wu and X. Zhao, Chin. J. Chem. Eng., 15, 872 (2007).

14. L.G. Chen, T. Wang and J. Tong, TrAC Trends Anal. Chem., 30, 1095 (2011).

15. L.S. Qing, J. Xiong, Y. Xue, Y.M. Liu, B. Guang, L.S. Ding and X. Liao, J. Sep. Sci., 34, 3240 (2011).

16. H.F. Zhang and Y.P. Shi, Analyst, 137, 910 (2012).

17. Y. Hiratsuka, N. Funaya, H. Matsunaga and J. Haginaka, J. Pharm. Biomed. Anal., 75, 180 (2013).

18. Z. Wang, H. Guo, Y. Yu and N. He, J. Magnet. Magn. Mater., 302, 397 (2006).

19. K.M. Giannoulis, G.Z. Tsogas, D.L. Giokas and A.G. Vlessidis, Talanta, 99, 62 (2012).

20. C.D. Stalikas, J. Sep. Sci., 30, 3268 (2007). 